\title{
BAILINI, SONIA (2016): LA INTERLENGUA DE LENGUAS AFINES. EL ESPAÑOL DE LOS ITALIANOS, EL ITALIANO DE LOS ESPAÑOLES. MILANO, EDIZIONI UNIVERSITARIE DI LETTERE ECONOMIA DIRITTO, 273 PÁGS.
}

\author{
G. Angela Mura \\ Universidad de Alicante / Grupo GRIALE \\ angela.mura@ua.es
}

La interlengua de lenguas afines. El español de los italianos, el italiano de los españoles presenta un análisis cuantitativo y cualitativo sobre las interlenguas de los aprendientes del español y del italiano desde una perspectiva bidireccional y lo hace a partir de dos corpus: el CORpus del ESPañol de los Italianos (CORESPI) y el CORpus del Italiano de los Españoles (CORITE). Los corpus empleados, uniformes y paralelos, recopilan textos escritos en etándem por correo electrónico entre aprendientes italianos de ELE de la Università Cattolica del Sacro Cuore (Campus de Brescia) y aprendientes españoles de ILE de la Universidad de Salamanca y de la Escuela Oficial de Idiomas de Barcelona (Terrassa).

El volumen se articula en dos partes: la primera, dedicada al marco teórico, se propone trazar el estado de la cuestión acerca de los estudios sobre la interlengua del español de los italianos y del italiano de los españoles. La segunda, más práctica y experimental, analiza la interlengua de estas dos lenguas afines en contexto en el seno de la lingüística de corpus. Ambas partes se dividen en tres capítulos cada una y siguen una estructura equilibrada y simétrica, pues se abren con un capítulo que presenta una visión de conjunto sobre las dos lenguas objeto de estudio, que en los capítulos siguientes se bifurca hacia cada una de ellas, profundizando en la idiosincrasia del español, por un lado, y del italiano, por el otro. Estas reflexiones paralelas, que se nutren mutuamente, se unifican en las conclusiones y permiten llegar a una propuesta común y novedosa acerca de las interlenguas de las dos lenguas afines estudiadas.

El concepto clave que impregna la obra y actúa como denominador común es el de interlengua, entendida como un sistema en evolución de carácter dinámico, variable, provisional, hipotético y permeable. En el capítulo 1 se delinean los rasgos constitutivos de la interlengua en relación con los procesos de adquisición de segundas lenguas y se presenta una panorámica de los estudios específicos sobre el análisis de las interlenguas del español y del italiano (Schmid 1994 y 1995; Calvi 1995, 1999 y 2003).

Para citar esta reseña / To cite this book review: Mura, G. Angela (2017). Reseña de Sonia Bailini, (2016): La interlengua de lenguas afines. El español de los italianos, El italiano de los españoles. Milano, Edizioni Universitarie Di Lettere Economia Diritto (273 páginas). ELUA, 31: 373-375. doi:10.14198/ELUA2017.31.20

Enlace / Link: http://dx.doi.org/10.14198/ELUA2017.31.20 
Los capítulos 2 y 3 presentan una recopilación bibliográfica razonada de los estudios empíricos sobre la interlengua del español y del italiano desde sus comienzos (años setenta y ochenta) hasta la actualidad (finales de 2014). Los trabajos reseñados se clasifican según parámetros funcionales establecidos, es decir, el año de publicación, el número y el nivel de los informantes, el tipo de interlengua analizada (oral o escrita), el método de obtención de datos (libre, guiado, test), el grado de especificidad, haciendo hincapié en la dimensión lingüística en que se centran (fonológico-ortográfica, morfosintáctica, léxica y pragmática). Este compendio comentado ofrece una panorámica integral del camino ya recorrido en este ámbito de análisis y sienta los cimientos para investigaciones futuras, al tiempo que pone de manifiesto la falta de estudios conjuntos y bidireccionales sobre las interlenguas del español y del italiano basados en corpus paralelos que brinden datos empíricos concretos para indagar sobre el efecto de la afinidad entre lenguas.

El capítulo 4 introduce la parte experimental de este volumen y se abre con una revisión de los corpus de interlengua del español de aprendientes italófonos y de la del italiano de aprendientes hispanófonos confeccionados hasta el momento. Esta panorámica detallada evidencia la existencia hasta la fecha de un único corpus que recopila simultáneamente datos de interlenguas de hablantes no nativos de E/LE e I/LE, es decir, el Corpus orale di interlingua spagnolo e italiano CORINÉI, fruto de la colaboración entre las universidades italianas de Salerno, Nápoles y Suor Orsola Benincasa y la universidad española de Alicante (https://dti.ua.es/en/teletandem-corinei/). CORESPI y CORITE, los corpus elaborados por la autora que sirven de base para el análisis empírico de esta obra, nacen para colmar estas lagunas y constituyen dos corpus longitudinales de interlengua recogidos a lo largo de siete meses en el seno del Proyecto Tándem. Se trata de una recopilación de la producción escrita de carácter espontáneo de discentes que pertenecen a cuatro niveles de competencia del MCER (del A1 al B2) y que se comunican entre ellos en parejas por correo electrónico. En este capítulo se explican las características y los criterios de construcción del corpus, la metodología y los materiales didácticos empleados para la recolección de datos y los parámetros de análisis.

En los capítulos 5 y 6 se lleva a cabo un análisis cuantitativo y cualitativo de los datos extraídos, respectivamente, del corpus CORESPI y del corpus CORITE. Siguiendo los mismos criterios de análisis para ambas interlenguas, se observan los rasgos fonológicoortográficos, morfosintácticos y léxico-semánticos. Las distintas categorías se estructuran en subcategorías que intentan evidenciar la variedad, la frecuencia y la persistencia de los errores intralinguales e interlinguales cometidos por los encuestados. La recopilación de ejemplos reales que ilustran los fenómenos descritos, al tiempo que afianza los conceptos teóricos tratados en la primera parte del volumen, demuestra la destreza de la autora en dar voz a la experiencia vivida de primera mano en el aula tanto de E/LE como de I/LE.

Esta propuesta de estudio de la interlengua del español y del italiano desde un punto de vista bidireccional y paralelo sugiere una nueva dimensión para la observación de la interlengua de lenguas afines, que convierte la afinidad como la esencia de la diferencia. El sistema dinámico y permeable que es la interlengua, en este caso, constituye el origen desde el cual se toma consciencia de los límites y de las potencialidades propios de la afinidad lingüística y guía el profesor de E/LE y de I/LE en la elaboración de materiales didácticos ad hoc para este tipo de aprendientes.

La estructura simétrica y equilibrada de este libro permite una lectura ágil y productiva 
del texto y la incorporación de ejemplos de uso reales favorece la comprensión de los conceptos tratados. Sin duda alguna el gran valor de la obra reside en el rigor con el que se examina el concepto de interlengua de lengua afines desde una perspectiva bidireccional español/italiano y en la elaboración de un corpus novedoso de interlengua de español y de italiano que sirve de base para trabajos tanto teóricos como empíricos de los hispanistas y de los italianistas. Se trata de un proyecto pionero en este ámbito de estudio y en relación con este par de lenguas, que brinda múltiples posibilidades de explotación didáctica para los profesores de E/LE en Italia y de I/LE en España. 